\title{
Design and Evaluation of a Millifluidic Insulator-Based Dielectrophoresis (DEP) Retention Device to Separate Bacteria from Tap Water
}

\author{
Shawn Jun ${ }^{\dagger}$, Cherisse Chun ${ }^{\dagger}$, Kacie Ho $[$ and Yong Li $*$ (1) \\ Department of Human Nutrition, Food, and Animal Sciences, University of Hawaii, 1955 East-West Road, \\ Honolulu, HI 96822, USA; shawnjun0203@gmail.com (S.J.); cchun4@hawaii.edu (C.C.); \\ kacieho@hawaii.edu (K.H.) \\ * Correspondence: liyong@hawaii.edu; Tel.: +1-808-956-6408; Fax: +1-808-956-4024 \\ + Co-first authors, these authors contributed equally to this work.
}

check for updates

Citation: Jun, S.; Chun, C.; Ho, K.; Li, Y. Design and Evaluation of a Millifluidic Insulator-Based Dielectrophoresis (DEP) Retention Device to Separate Bacteria from Tap Water. Water 2021, 13, 1678. https:// doi.org/10.3390/w13121678

Academic Editors: Qilin Wang,

Dongbo Wang, Yingqun Ma, Jing Sun and Li Gao

Received: 26 May 2021

Accepted: 14 June 2021

Published: 17 June 2021

Publisher's Note: MDPI stays neutral with regard to jurisdictional claims in published maps and institutional affiliations.

Copyright: (c) 2021 by the authors. Licensee MDPI, Basel, Switzerland. This article is an open access article distributed under the terms and conditions of the Creative Commons Attribution (CC BY) license (https:/ / creativecommons.org/licenses/by/ $4.0 /)$.

\begin{abstract}
Water is a basic necessity critical to the survival of all living beings. However, many people around the world do not have consistent access to uncontaminated drinking water. Traditional water treatment methods, such as filtration and disinfection, require physical or chemical disinfectants and are prone to fouling. Dielectrophoresis (DEP) enables a system whereby polarized bioparticles exhibit lateral movement under the influence of applied, non-uniform electric fields. A single-stage, continuous flow, millimeter-sized DEP device was designed and fabricated to remove Escherichia coli $\mathrm{K} 12$ from contaminated tap water. Glass beads were used to alter the electric field distribution and create zones of high electric field to trap bacterial cells. The effect of varied voltages, flow rates and bead sizes on the removal efficiency was studied. The highest removal efficiency of $E$. coli $\mathrm{K} 12$ was $99.9 \%$, with the device set at $60 \mathrm{~V}$, a flow rate of $1.0 \mathrm{~mL} / \mathrm{min}$ and a $200 \mu \mathrm{m}$ bead size. Higher applied voltages, slower flow rates, and smaller bead sizes led to an increased reduction in bacteria. An optimized macro-scale system - with multiple stages of DEP—could be suitable for commercial use and would be an effective method of removing pathogens from polluted tap water.
\end{abstract}

Keywords: glass beads; DEP; water treatment; Escherichia coli; electric field

\section{Introduction}

Clean drinking water is believed to be a fundamental human right and a critical necessity for maintaining the health and sustainability of all life on Earth [1]. According to the 2017 estimate by the World Health Organization and UNICEF [2], 844 million people worldwide are water insecure and do not have access to even a basic drinking water supply. Grey and Sadoff [3] define water security as the accessibility of acceptable quality and quantity of water required for physical, ecological and economic sustainability coupled with the assurance of adequate levels of safety when considering potential water-related risks and impacts. Unfortunately, freshwater natural resources are being threatened in many parts of the world due to human activities such as urbanization and industrialization. Climate change and population growth are also contributing factors to water insecurity $[4,5]$. Proper water treatment technology development and maintenance are key in reducing waterborne illnesses, decreasing poverty, encouraging economic growth and improving water security in developing countries [6].

E. coli O157:H7-a typical example of a foodborne pathogenic microorganism-can be transmitted through recreational and drinking means, namely by swimming in a contaminated body of water or drinking from an unchlorinated municipal water supply [7]. Wang and Doyle [8] sought to determine the survival characteristics of E. coli O175:H7 in water by placing strains in sterilized municipal water, reservoir water and lake water used for swimming for 91 days at different temperatures. Their results showed that E. coli O157:H7 
had persisted in the water and caused serious illnesses due to its high survivability in water and low infectious dose.

Conventional water treatment techniques, such as disinfection, desalinization and decontamination, are challenging to manage and require the addition of a considerable amount of chemicals and energy [9]. Often, these techniques call for significant amounts of engineering knowledge, capital, and infrastructure development, making such technology unattainable and unrealistic for most developing countries [10]. Although drinking water disinfection is critical for killing the pathogens that cause waterborne illnesses, chemical disinfectants are known to form disinfection by-products (DBPs) that can have serious adverse health effects [11]. Chlorine, a common disinfectant, reacts with natural organic matter (NOM) to form trihalomethanes (THMs), such as chloroform, bromodichloromethane, chlorodibromomethane, and bromoform, which have been linked to bladder, colon, and rectal cancers, as well as reproductive harm [12].

In recent years, membrane filtration technology has been used to render water safe to drink, either as a phase in conventional water treatment processes or at the immediate point of consumption. Such pressure-driven liquid membrane processes as ultrafiltration, microfiltration, nanofiltration, and reverse osmosis are often used to remove particulates from drinking water through size exclusion [13]. Membranes are fine films composed of synthetic organic or inorganic materials that selectively isolate an array of matter from a liquid by trapping particulates on its surface or within its matrix [14]. This trapping mechanism often leads to membrane fouling, caused by pore blockages and cake formation, which is considered to be its most detrimental side effect. Fouling results in reduced membrane particulate capacity due to the accumulation of biological, chemical, and physical impurities naturally present in water [15]. Once irreversibly fouled, the total cost to operate the system goes up due to maintenance downtime, increased labor, and the purchase of replacement units. Membrane filtration is also the most energy-intensive water disinfection method since a high operating pressure must be applied to overcome the reduced membrane permeability caused by fouling over time [16,17].

Dielectrophoresis (DEP) is a well-established phenomenon that can serve as an effective and non-destructive electrokinetic transport mechanism for an array of bioparticles [18]. DEP occurs when an uncharged, neutral particle is exposed to a non-uniform electric field, and the particle becomes polarized. The polarized particle, also known as a dipole, has Coulomb forces of different magnitudes acting on each of its sides, resulting in a net translational force, referred to as $F_{D E P}$. The generated dipole may either be in alignment with or directed against the electric field, based on whether the particle's permittivity is greater or less than the permittivity of the suspending medium, respectively [19]. Particles that experience positive-DEP move in the direction of the electric field gradient (see Figure $1 a)$, whereas particles that experience negative-DEP move in the opposite direction, away from the field gradient (see Figure 1b) [20]. The dielectrophoretic force experienced by a particle is directly dependent on its "electrical phenotype," which includes the particle's size, shape, permittivity and conductivity [21]. 




Figure 1. Direction of the cell translation based on its DEP response: (a) positive-DEP cell movement; and (b) negative-DEP cell movement (adapted from [22]).

DEP is often used to sort and concentrate cells, bacteria and viruses within a microfluidic device. Microfluidics has emerged as a distinct new field of research with numerous applications in biological analysis [23]. However, DEP is often restricted due to the use of traditional planar DEP electrodes for significant reasons. First and foremost, the gradientand therefore also DEP forces-is mostly normal to the direction of flow. Instead, DEP forces must be aligned so as to counter Stokes drag for effective trapping. Additionally, the $E$ field gradient does not sufficiently nor effectively penetrate the electrode gap. When a quicker flow rate is applied, the removal efficiency of traditional DEP devices is severely limited [24]. Traditional DEP typically uses nonparallel metal electrodes which come into direct contact with the liquid medium. The embedded electrode systems often encounter issues with Joule heating produced by direct or alternating current in the areas near the electrode tips. The resulting thermal convection may interrupt cell migration [25]. Other limitations to these types of electrodes include electrode fouling, bubble formation, a complex fabrication process and electrochemical reactions on the electrode surface [26]. Many DEP studies have also utilized thin metal electrodes that are fabricated using relatively complicated photolithographic techniques.

Another challenge associated with DEP is the estimation of the appropriate channel width and size to facilitate effective particle manipulation. Electric fields of high magnitude are only generated in the narrow electrode gap directly near the edges of the electrodes, and it is often recognized that the magnitude of DEP force is greatly reduced as the distance from the electrodes increases [27]. As a result, bioparticles only experience significant dielectrophoretic forces while close to the electrode surface. Bioparticles located farther away from electrodes are not at all influenced by DEP forces. Consequently, devices with 
channel sizes exceeding approximately $400 \mu \mathrm{m}$ in width are inappropriate for DEP trapping and filtering due to inadequate $F_{D E P}$ strength [27].

An insulator-based DEP (iDEP) system is a possible alternative to overcome many of the hurdles experienced with traditional DEP [28]. iDEP, also known as electrodeless DEP, is a technique in which voltage is applied to an array of insulating obstacles with two remote electrodes that span the complete width of the dielectric array. The spatial nonuniformities in the electric field are created by positioning the insulating obstacles inside the device channel and then passing a remotely applied voltage across that channel [28]. When the electric field is applied in an iDEP format, the electric field lines are bent between each insulating obstacle, resulting in the crucial non-uniform electric field necessary to facilitate DEP forces [29]. The insulating structures are chemically inert and relatively strong while also less prone to fouling than traditional embedded electrodes [26]. Moreover, the fabricated iDEP devices can be simply and inexpensively made using insulating materials such as plastics and are ideal for large-volume and high-throughput purposes [30].

The concept of iDEP was first explained by Masuda, Itagaki and Kosakada [31], who aimed to detect very fine nanoparticles. Afterward, Cummings and Singh [32] successfully used DC dielectrophoretic concentration to trap particles with a uniform array of circular insulating posts fabricated using isotropic glass etching. More recently, Chou et al. [33] used insulating quartz instead of metal electrodes to concentrate double- and single-stranded DNA. Zhou, Imamura, Suehiro and Hara [34] used a device full of insulating glass beads to eliminate yeast cells from water. McGraw, Davalos, Brazzle, Hachman and Hunter [35] were able to selectively concentrate, trap and release bacteria and inert particles using iDEP within a polymeric microfluidic device. The device consisted of microfluidic channels and arrays of internally located insulating posts made using standard wet-etch techniques in glass. [35]. Their device was also applied to the detection of waterborne pathogens. Lapizco-Encinas, Simmons, Cummings and Fintschenko [36] aimed to selectively trap Gram-negative E. coli from three Gram-positive Bacillus species using a DC voltage applied across a glass microchannel with insulating posts. Since E. coli had a greater negative DEP mobility than the Bacillus species, their iDEP separation method proved successful. The same research group also trapped live E. coli cells from a mixture of dead E. coli and inert polystyrene beads based on their dielectrophoretic mobility [37].

Dielectric glass beads have low electrical conductivity $\left(10^{-11} \sim 10^{-15} \mathrm{~S} / \mathrm{m}\right)$ with electrically insulating properties. When the glass beads are placed in the gap between two parallel plate electrodes and then subject to a non-uniform electric field, they can alter their surrounding field distributions; therefore, zones of high electric field are generated on each bead's surface. Thus, with iDEP, numerous spots of high field span the insulating array; this differs from traditional DEP, where a high field gradient only exists near the electrodes. Additionally, to increase the areas of high field, extra insulating glass beads can simply be packed inside the device. By applying a voltage to the electrodes, a positive DEP force can attract suspended bioparticles that flow through the gaps in between the beads (Figure 2a). If the strengths of Stokes drag forces are less than that of the net DEP force acting on the bioparticle, that particle can adhere to the surface of the bead [34]. Since the size of the gap between each insulating bead far exceeds that of the particle size, the possibility for fouling or clogging, which is a major disadvantage with membrane filters, is effectively removed. Additionally, by removing the AC signal — and hence the electrodes' voltage- the particles detach and flow past the glass beads without attaching to the surface (Figure 2b). This electrically controlled function serves as a simple cleaning method whereby the particles can be removed from the device by cutting the power supply and running fluid through the channel [38].

This study presents the design and evaluation of an electrostatic iDEP filter used to remove E. coli $\mathrm{K} 12$ from contaminated tap water. E. coli $\mathrm{K} 12$ was chosen for this study because it is a commonly used surrogate for E. coli O157:H7, a serious emerging pathogen and an indicator of fecal microbiological contamination in water. The aim of this DEP retention device was to overcome the many critical hurdles encountered when using traditional 
planar electrodes: low field gradient penetration depth and strength, low flow throughput and small channel size. Additionally, since the metal electrodes are remotely located outside of the channel and do not come into direct contact with the liquid medium, Joule heating and fouling issues are not of significant concern. Design considerations-including the compatibility of the different materials used, pressure tolerance, price, sturdiness and ease-of-use-were considered when designing the iDEP device.

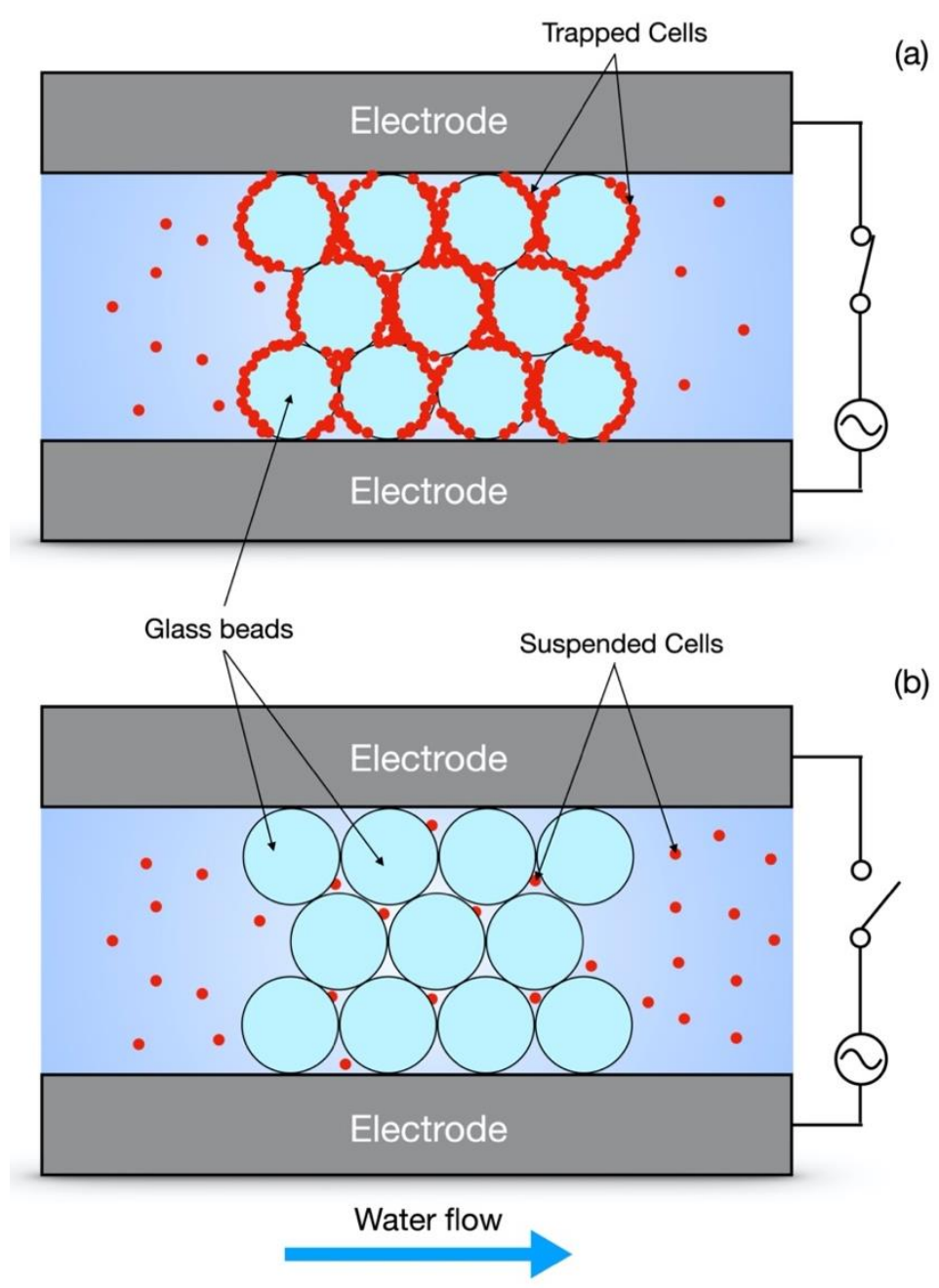

Figure 2. Basic principles behind the dielectric glass bead DEP device: (a) with voltage supplied to the electrodes, the cells attach to the surface of the electrodes when subject to positive-DEP forces; (b) without voltage supplied to the electrodes, the cells flow past the glass beads through the gap spaces and do not adhere to the beads (adapted from [38]).

\section{Materials and Methods}

\subsection{Device Design and Fabrication}

Each component of the iDEP device, including the channel body, ventilation cap, channel insert, and inlet and outlet cap, was designed with Solidworks (Dassault Systèmes SolidWorks Corporation, Waltham, MA, USA). The rectangular channel was $1 \mathrm{~cm} \times 1 \mathrm{~cm} \times 6.5 \mathrm{~cm}$ to give a total holding capacity volume of $6.5 \mathrm{~mL}$. The mold components were then printed on a Form 2 desktop stereolithography (SLA) 3D printer (Formlabs, Inc., Somerville, MA, USA) using photosensitive resin. After printing, each piece was washed in isopropyl alcohol to remove any uncured resin still attached to the surface and then cured with ultraviolet (UV) light for $60 \mathrm{~min}$ at $62^{\circ} \mathrm{C}$.

Figure 3 a shows that the inner walls of the channel body were covered with a very porous pattern; this allowed the PDMS to adhere to the inside of the channel tightly. The 
channel insert was secured to the bottom of the DEP channel body with four machine screws. The prepared PDMS was poured into the channel body and around the insert to create a one cm-thick layer of the silicone just around the channel walls. The ventilation cap was attached to the top of the body to hold the insert in the channel's center and encourage even heating throughout (Figure $3 \mathrm{~b}$ ). The device was baked for $12 \mathrm{~h}$ at $62{ }^{\circ} \mathrm{C}$ and allowed to sit at room temperature for $48 \mathrm{~h}$.

(b)

(a)

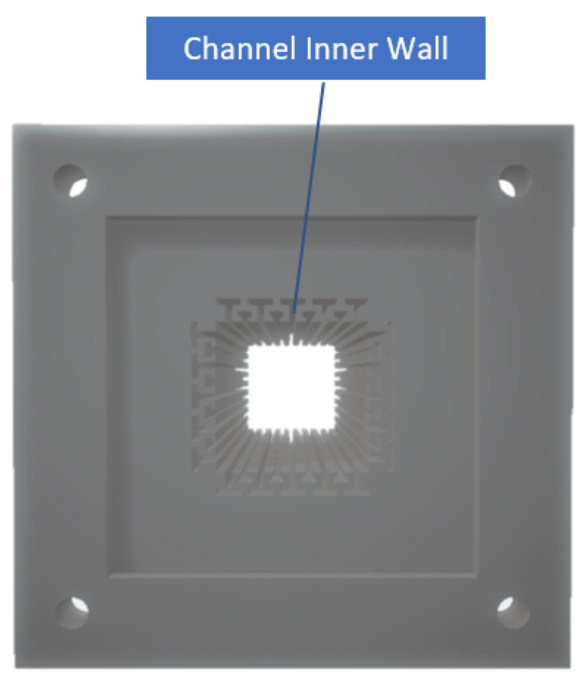

Ventilation Cap

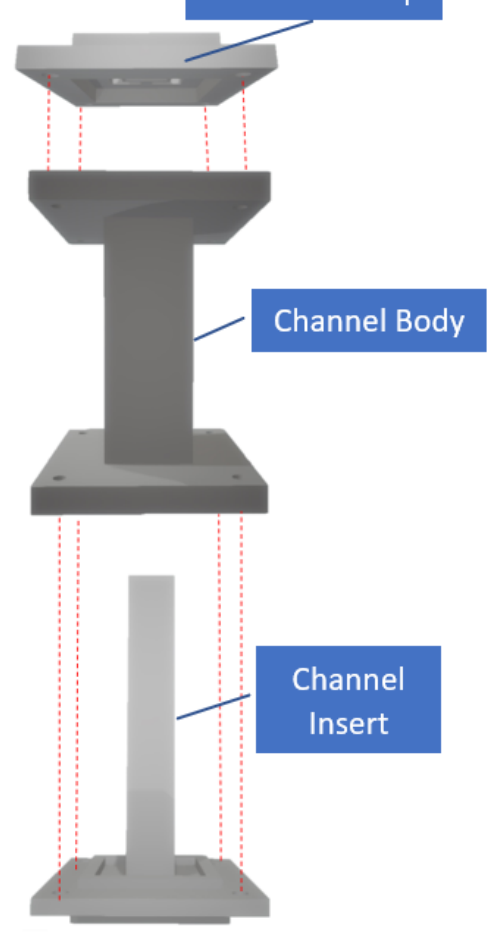

Figure 3. The coating of the inner channel walls with PDMS: (a) Rigid and porous structure created to hold the PDMS inside the channel, and (b) Insert placed inside the channel for molding the PDMS around the walls of the channel.

Once the PDMS was dried, the ventilation cap and channel insert were removed from the body. 100-micron stainless steel meshes were placed at both the inlet and the outlet of the channel body and then sealed in place with PDMS to prevent any glass beads from escaping. Rubber gaskets were placed at each end to avoid leakages, and the inlet and outlet caps were secured with screws (Figure 4). The total volume of glass beads and empty space within the device was approximately $3.4 \mathrm{~mL}$ and $3.1 \mathrm{~mL}$, respectively.

For the electrodes, $0.5 \mathrm{~mm}$-thick stainless steel was cut into two $5 \mathrm{~cm} \times 2.5 \mathrm{~cm}$ pieces and attached to the sides of the channel (Figure 4). Flexible tubing (Saint-Gobain Performance Plastics, Akron, OH, USA) was connected to the inlet and outlet caps to allow sample water to flow in and out of the device. A polypropylene female Luer lug (Nordson Medical, Fort Collins, CO, USA) was placed on one end of the tubing to allow attachment to the syringe pump system for collection.

\subsection{Experimental Set-Up}

The DEP device was placed on a leveled platform to ensure that it was level without the employment of inclined gravity throughout the duration of the experiments. A syringe pump (Model: Fusion 100, Chemyx Inc., Stafford, TX, USA) was used to pull the E. coli sample through the device at a constant flow rate, as shown in Figure 5. After the contaminated tap water was passed through the DEP device, the resulting suspension at the outlets was collected with syringes and used for microbial analysis. A frequency generator (Model: 33210A, Keysight Technologies, Santa Rosa, CA, USA) attached to a voltage amplifier 
(Model: HA-205, Pintek Electronics, TW, USA) was used to generate the voltage that was applied to the electrodes and control the frequency. The applied frequencies and voltages were carefully monitored throughout each experiment using an oscilloscope (Model: TDS 2014, Tektronix Inc., Beaverton, OR, USA).
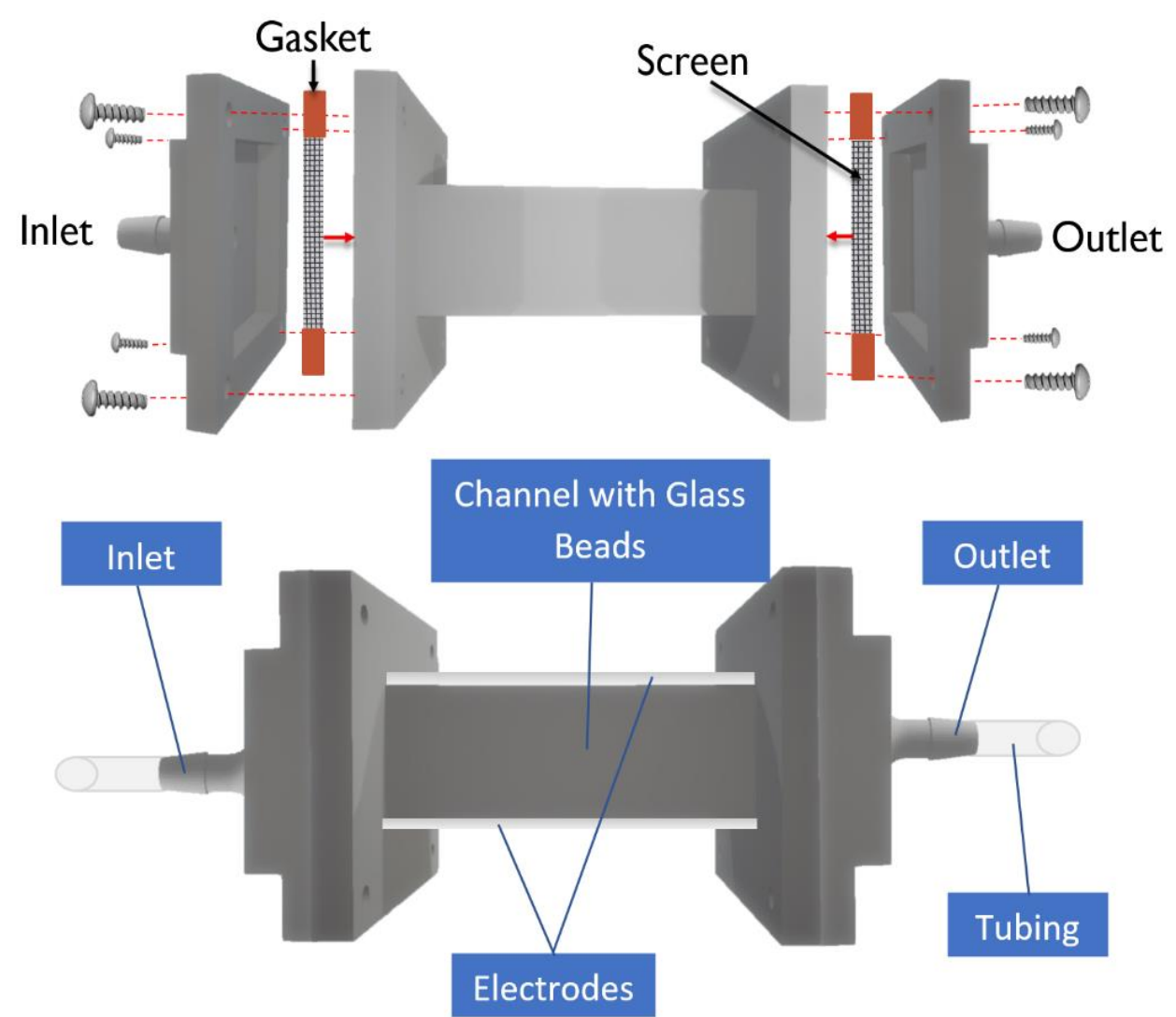

Figure 4. The layer-by-layer iDEP device assembly.

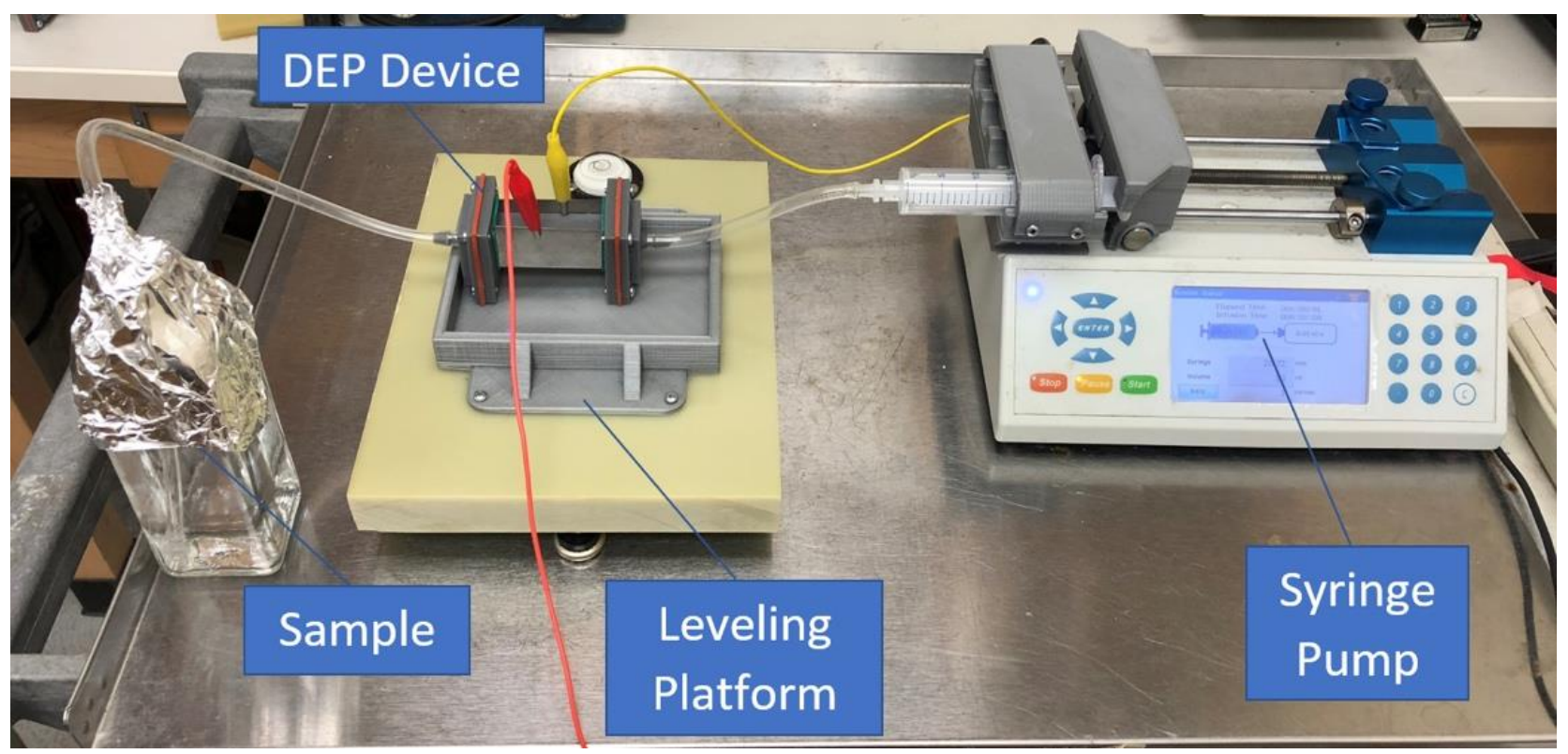

Figure 5. The iDEP device was placed on a leveled platform with a syringe pump attached to ensure a continuous flow of the sample through the device. 


\subsection{Microbial Preparation}

The procedure used to prepare the E. coli sample follows the method described by Cebricos et al. [39]. Frozen E. coli K12 stock was obtained from the Food Microbiology Laboratory, a Biosafety Level II lab at the University of Hawaii in Manoa. Precisely $100 \mu \mathrm{m}$ of frozen E. coli $\mathrm{K} 12$ stock was inoculated into $10 \mathrm{~mL}$ of tryptic soy broth (TSB) and incubated at $37^{\circ} \mathrm{C}$ for $24 \mathrm{~h}$. After incubation, several microcentrifuge tubes $(1.7 \mathrm{~mL})$ were each filled with $1 \mathrm{~mL}$ of the incubated $E$. coli $\mathrm{K} 12$ solution. The microcentrifuge tubes were placed in a centrifuge for $10 \mathrm{~min}$ at $6000 \times \mathrm{g}(8000 \mathrm{rpm})$. After centrifugation, the supernatant was removed and replaced with $1 \mathrm{~mL}$ of phosphate-buffered saline (PBS). The cells were resuspended in the PBS and vortexed until mixed. This washing procedure with PBS was repeated three more times to reduce the conductivity. After the last wash, the supernatant was removed, and $1 \mathrm{~mL}$ of sterilized tap water was mixed with each of the cell pellets in the microcentrifuge tubes. The contents were added into the glass sample bottle to generate a starting bacterial cell concentration of $1 \times 10^{5} \mathrm{CFU} / \mathrm{mL}$ and vortexed gently until thoroughly mixed.

\subsection{Experimental Design and Quantification of Removal Efficiency}

In order to observe the effects of different experimental parameters on the percent reduction in $E$. coli $\mathrm{K} 12$, varying combinations of several voltages, flow rates and bead sizes were tested. Three different voltages-20 V, $40 \mathrm{~V}$ and $60 \mathrm{~V}$-were applied to the electrodes while the frequency was held constant at $1 \mathrm{MHz}$ for all experiments. The upper limit of input voltage, $60 \mathrm{~V}$, was selected to prevent cell lysis preemptively. At higher potentials, cells may lyse due to strong electric fields; additionally, Joule heating may burn cells inside the channel. Three different flow rates $(1.0 \mathrm{~mL} / \mathrm{min}, 1.5 \mathrm{~mL} / \mathrm{min}$ and $2.0 \mathrm{~mL} / \mathrm{min})$ were chosen based on a work by Cebricos et al. [37]. Three specific bead sizes $(200 \mu \mathrm{m}, 300 \mu \mathrm{m}$ and $500 \mu \mathrm{m}$ ) were available for purchase from a commercial vendor (Sigma Aldrich, St. Louis, MO, USA). Tap water samples were collected at the device outlet every $10 \mathrm{~min}$ for a total of $120 \mathrm{~min}$ per trial. The samples were serially diluted using peptone water and plated using the spread plate method on BD BBL ${ }^{\mathrm{TM}}$ MacConkey Agar (Becton, Dickinson and Company, Sparks, MD, USA). The plates were then incubated at $37^{\circ} \mathrm{C}$ for $24 \mathrm{~h}$ before being analyzed and counted.

The performance of the glass bead DEP device was measured based on its removal (or trapping) efficiency. This removal efficiency was determined by comparing the concentration of E. coli $\mathrm{K} 12$ cells before and after treatment with the device, as defined using the following equation, where $n$ is the number of bacteria cells $(\mathrm{CFU} / \mathrm{mL})$ :

$$
\text { Removal Efficiency }=\frac{\left(n_{\text {Inlet }}-n_{\text {Outlet }}\right)}{n_{\text {Inlet }}} \times 100 \%
$$

In addition, the log reduction in bacterial cells was also calculated using the equation below:

$$
\text { Log Reduction }=\left(\log _{10} n_{\text {Inlet }}-\log _{10} n_{\text {Outlet }}\right)
$$

The data were analyzed via one-way ANOVA tests using the Statistical Analysis System software (SAS Institute, Cary, NC, USA). All experiments were conducted in triplicate, with data expressed as the mean added with the standard deviation. Additionally, the separation of means was tested by Duncan's multiple range test at a probability level of $p<0.05$.

\section{Results and Discussion}

\subsection{Effects of Voltage on Removal Efficiency}

The effects of applied voltages on the removal efficiency of the iDEP device were tested by applying three different voltages: $20 \mathrm{~V}, 40 \mathrm{~V}$ and $60 \mathrm{~V}$ for $120 \mathrm{~min}$ (Figure 6). The glass bead size and flow rate were kept constant for all experiments at $200 \mu \mathrm{m}$ and $1.0 \mathrm{~mL} / \mathrm{min}$, respectively. The highest removal efficiency recorded during the $120 \mathrm{~min}$ 
period was $99.9 \%$ at $60 \mathrm{~V}$, followed by $87.4 \%$ at $40 \mathrm{~V}$ and $65.4 \%$ at $20 \mathrm{~V}$ (Figure 7 ). There was a 2.9-log reduction for $60 \mathrm{~V}$, while the $\log$ reduction for $20 \mathrm{~V}$ and $40 \mathrm{~V}$ remained below $1 \mathrm{log}$. The removal efficiency was greatest at the highest applied voltage, and all three voltages were significantly different from one another. Additionally, the standard deviation for the lower voltages was greater than the standard deviation at the higher applied voltages.

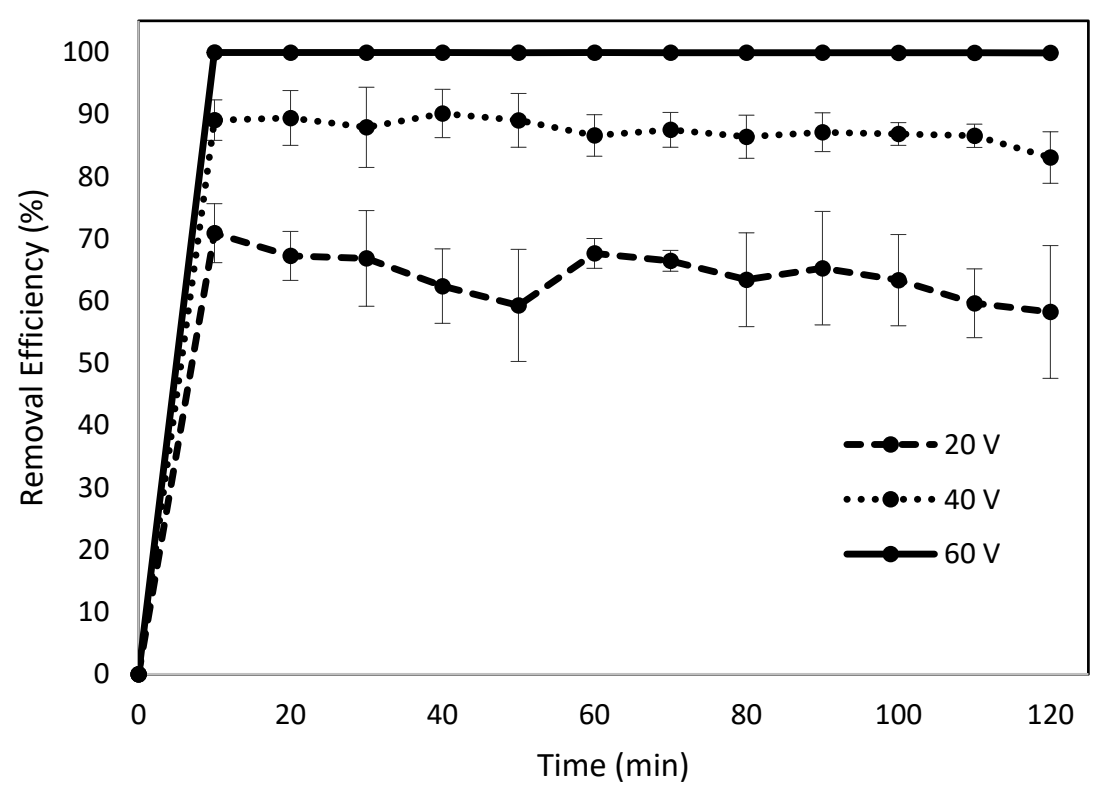

Figure 6. The effects of three different voltages on removal efficiency over a $120 \mathrm{~min}$ period (bead size $=200 \mu \mathrm{m}$, flow rate $=1.0 \mathrm{~mL} / \mathrm{min}$ ).

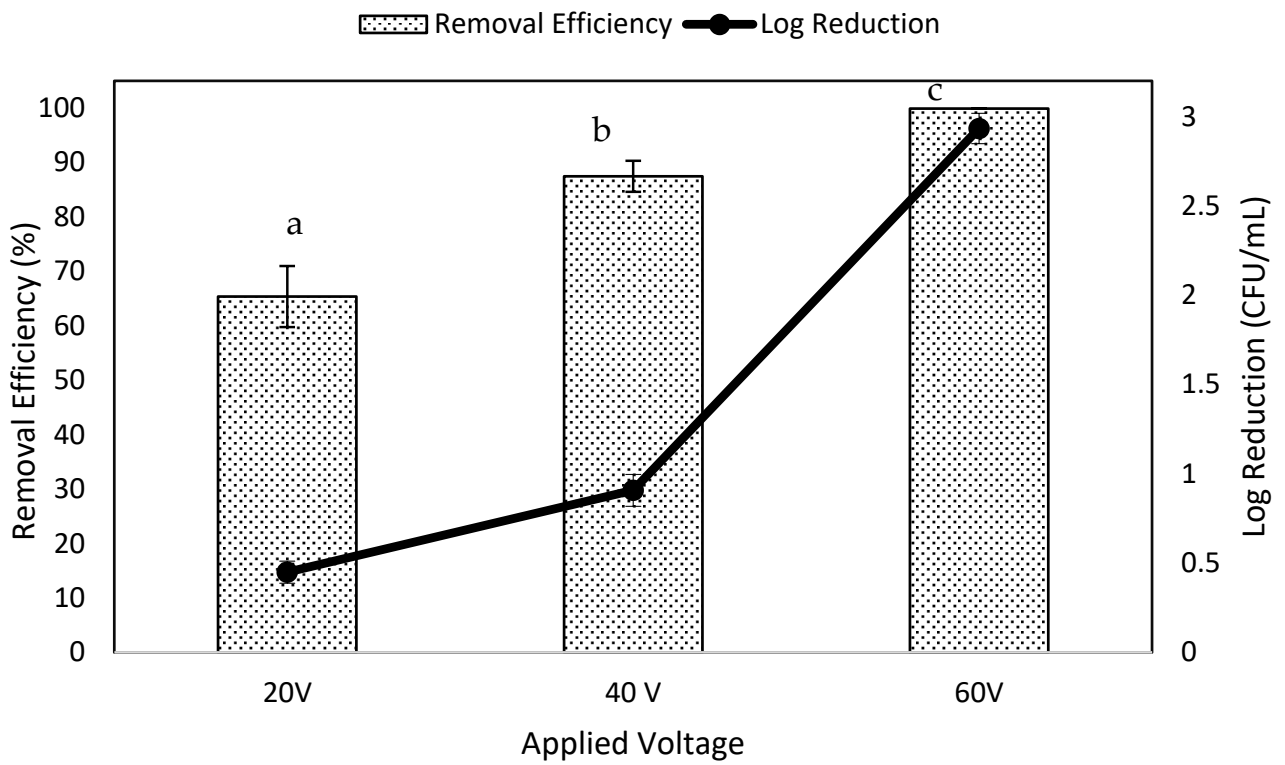

Figure 7. Comparison of the average removal efficiency and log reduction when three different voltages are applied. Different letters indicate significant differences among the applied voltages $(p<0.05)$.

Research by Wang et al. [40] used a microchip with a DEP selective filter to determine the effect of applied voltage on the sorting efficiency of yeast cells. They found that removal efficiency increased with increasing applied voltages from $60 \%$ at $5 \mathrm{~V}$ to $90 \%$ at 20 V. Additionally, Abidin, Baik, Hafifudin, and Markx [41] studied the dielectrophoretic separation of yeast cells using a high-gradient electric field system comprised of glass beads sandwiched between two cylindrical electrodes. At 20V, they achieved a removal 
efficiency of $56 \%$, but at $60 \mathrm{~V}$, this number was increased to $80 \%$. Since the dielectrophoretic force is dependent on the electric field intensity, $\nabla|E|^{2}$, the magnitude of the DEP force experienced by cells increases when the voltage is increased. The higher applied voltages are necessary to overcome the Stokes drag forces through the device channel so that the cells may be trapped and removed from the stream of water [42]. Additionally, when the voltage is higher, the particle velocity is sped up, resulting in a quicker separation process. This phenomenon is due to the intensification of the electroosmotic flow under strong electric fields [43]. However, an upper limit for the voltage must be considered since cells may lyse due to strong electric fields created by the higher potential difference. Joule heating may also occur and burn the cells inside the channel.

\subsection{Effects of Flow Rate on Removal Efficiency}

Then, the effect of flow rate variation was tested using three different flow rates: $1.0 \mathrm{~mL} / \mathrm{min}, 1.5 \mathrm{~mL} / \mathrm{min}$, and $2.0 \mathrm{~mL} / \mathrm{min}$. Figure 8 shows the removal efficiency of $E$. coli K12 as a function of flow rate, at an applied voltage of $60 \mathrm{~V}$, frequency of $1 \mathrm{MHz}$ and $200 \mu \mathrm{m}$ bead size. The highest removal efficiency achieved was $99.9 \%$ at $1.0 \mathrm{~mL} / \mathrm{min}$, the slowest flow rate tested, followed by $80.5 \%$ and $67.4 \%$ for the flow rates of $1.5 \mathrm{~mL} / \mathrm{min}$ and $2.0 \mathrm{~mL} / \mathrm{min}$, respectively. There was a $2.9-\log$ reduction for $1.0 \mathrm{~mL} / \mathrm{min}$ and a less than 1-log reduction for the two faster flow rates (Figure 9). The standard deviation was greatest at $2.0 \mathrm{~mL} / \mathrm{min}$, and there was a significant difference among all three flow rates.

Low trapping efficiencies at higher flow rates are thought to result from the loss of captured cells caused by viscous drag forces [40]. Dielectrophoretic separation is often described as a balance of competing forces that gives rise to a net force that dictates the movement of the cell. Suppose the forces (i.e., viscous drag, diffusional and lift forces) that work to move the bacteria away from the regions of strong electric fields are greater than the forces (i.e., DEP, dipole, gravitational) holding them in place at the matrix. In that case, the bacteria will escape from the DEP channel [44]. High flow rates increase the drag force, which consequently washes the bacteria from the bead's surface.

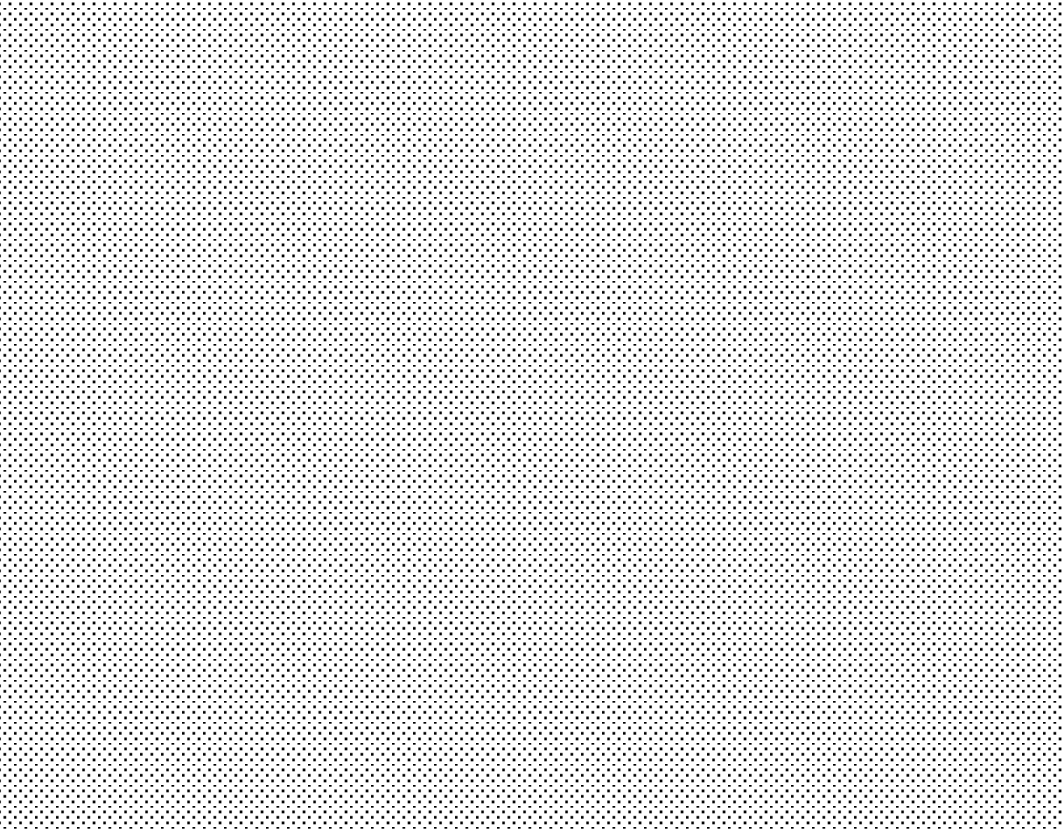

Figure 8. The effects of three different flow rates on removal efficiency over a $120 \mathrm{~min}$ period (bead size $=200 \mu \mathrm{m}$, voltage $=60 \mathrm{~V}$ ). 


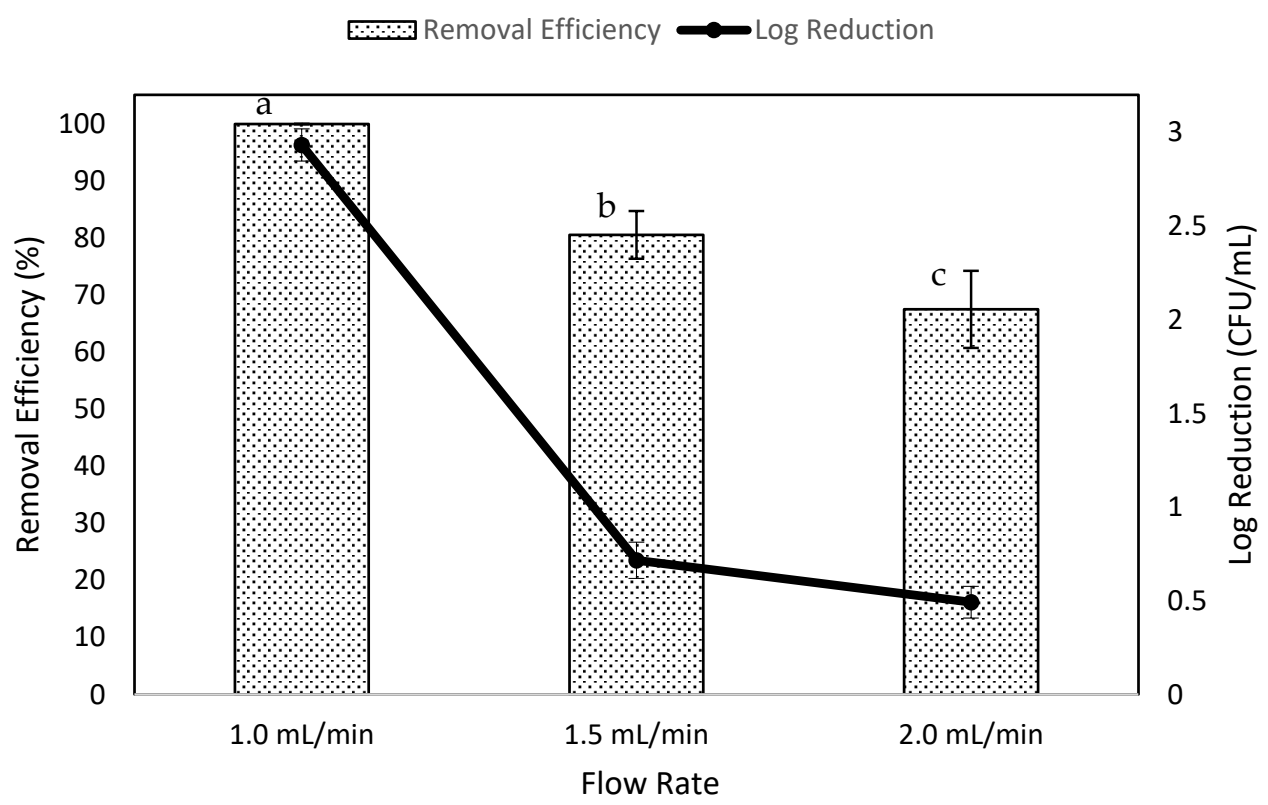

Figure 9. Comparison of the average removal efficiency and log reduction among three different flow rates. Different letters indicate significant differences among the different flow rates $(p<0.05)$.

\subsection{Effects of Bead Size on Removal Efficiency}

Figure 10 shows the effect of bead sizes on the trapping of E. coli $\mathrm{K} 12$ by testing three different bead sizes for $120 \mathrm{~min}$. The voltage was kept at $60 \mathrm{~V}$, and the flow rate was maintained at $1.0 \mathrm{~mL} / \mathrm{min}$. There was a $99.9 \%$ removal of bacteria when the iDEP device was packed with $200 \mu \mathrm{m}$ dielectric glass beads, followed by a $76.2 \%$ reduction for $300 \mu \mathrm{m}$ beads and a $47.6 \%$ reduction for $500 \mu \mathrm{m}$ glass beads. The log reduction for the $300 \mu \mathrm{m}$ and $500 \mu \mathrm{m}$ glass beads were both well below $1 \mathrm{log}$, while the $200 \mu \mathrm{m}$ glass beads facilitated a 2.9-log reduction in bacteria (Figure 11). The $500 \mu \mathrm{m}$ beads had the largest standard deviation, and there was a significant difference between all three bead sizes.

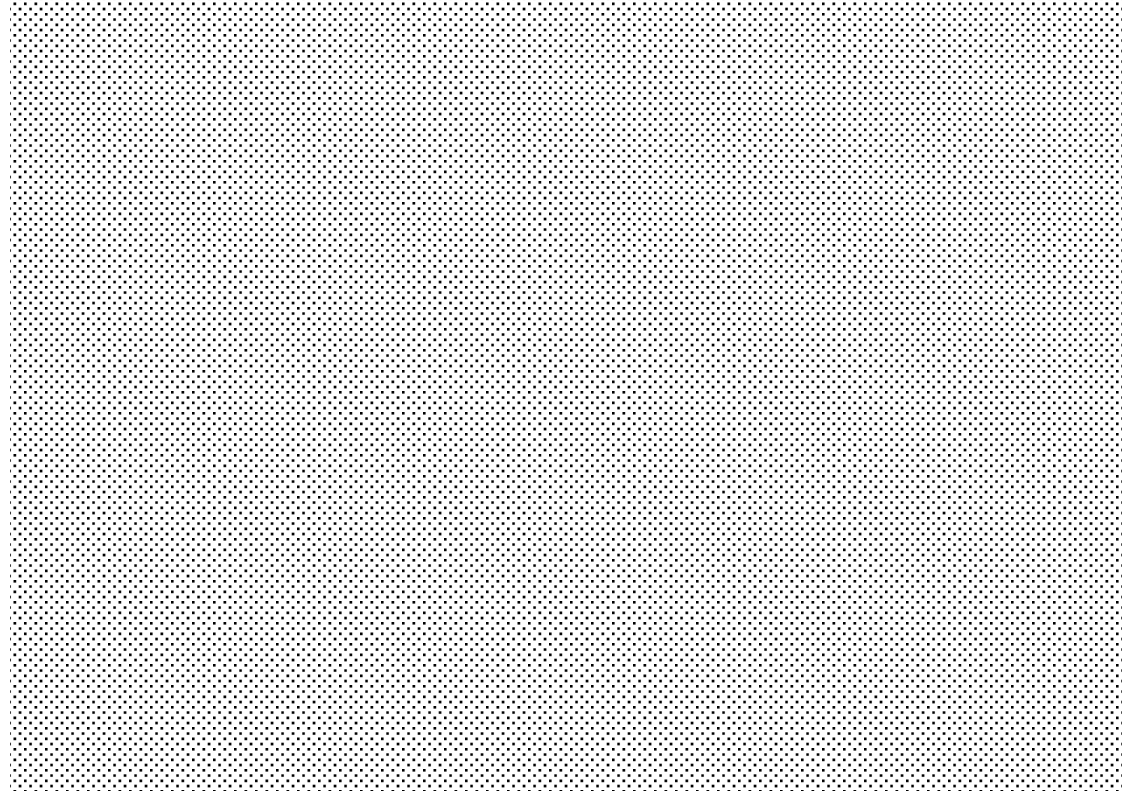

Figure 10. The effects of three different bead sizes on removal efficiency over a $120 \mathrm{~min}$ period (voltage $=60 \mathrm{~V}$; flow rate $=1.0 \mathrm{~mL} / \mathrm{min}$ ). 


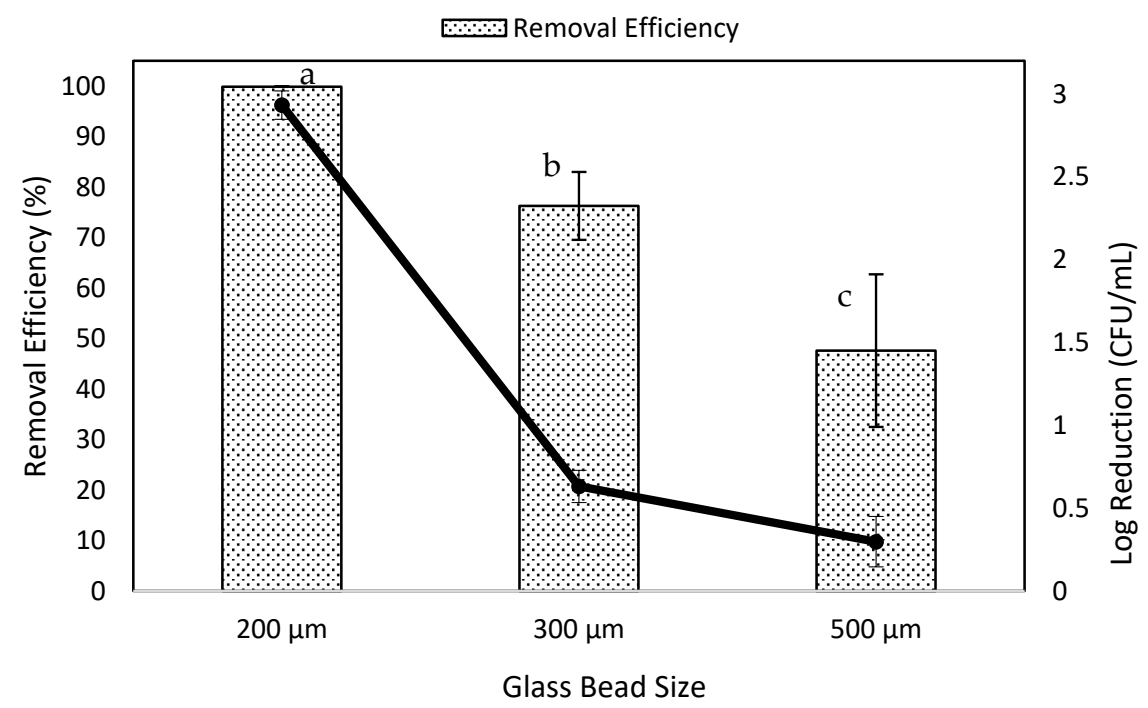

Figure 11. Comparison of the average removal efficiency and log reduction among three different bead sizes. Different letters indicate significant differences among the different bead sizes $(p<0.05)$.

Since glass beads have a relative permittivity of 4.5 , they must create distortions in electric field patterns [41]. Strong electric fields are generated on the surface of each insulating glass bead and at each of its contact points. For this reason, the total surface area of the beads and the number of beads present would directly correlate with the number of bacteria that could adhere to the beads' surfaces. For the $200 \mu \mathrm{m}, 300 \mu \mathrm{m}$ and $500 \mu \mathrm{m}$ glass beads, the total bead surface area is approximately $0.102 \mathrm{~m}^{2}, 0.068 \mathrm{~m}^{2}$ and $0.041 \mathrm{~m}^{2}$, respectively. The $200 \mu \mathrm{m}$ bead size has the greatest total surface area and beads contained within the device and, therefore, the highest bacteria trapping capacity.

\section{Conclusions}

This study has demonstrated that an iDEP device filled with glass beads can continuously and effectively trap live $E$. coli $\mathrm{K} 12$ from contaminated tap water. The highest removal efficiency achieved was $99.9 \%$, with $60 \mathrm{~V}$ supplied to the electrodes, a $1.0 \mathrm{~mL} / \mathrm{min}$ flow rate, and $200 \mu \mathrm{m}$ bead sizes. Higher applied voltages, slower flow rates, and smaller bead sizes seemed to lead to larger reductions in the bacteria in water. A non-uniform electric field was generated by applying an AC electric field across the millimeter-sized channel packed with insulating glass beads. Regions of high electric field intensity were generated on the beads' exteriors so that $E$. coli would experience positive-DEP forces and adhere to these surfaces. This device displayed DEP retention, a separation method in which positive-DEP forces are used to compete with the drag forces caused by fluid flow. Since particles subject to strong positive-DEP forces are trapped at their minimum DEP potential energy positions, they are secured in place and do not get swept away with the suspending fluid [45]. The use of electrical forces to manipulate bioparticles continues to show great potential in many areas of research. iDEP, which uses insulating hurdles, protrusions, or obstacles to create spatial non-uniformities within the device channel, is a promising alternative to traditional microfluidic DEP devices. Some of the major drawbacks associated with conventional DEP, such as low throughput, contamination, fouling, bubbling near the electrode surface, and expensive and laborious fabrication, can be remedied by using iDEP in its place [46].

Unlike membrane filtration, an iDEP filter does not result in costly fouling issues that require frequent maintenance and replacement. Since the bacteria can be detached from the glass by simply turning off the AC power supply to the electrodes, cleaning the device is straightforward and economical. iDEP can also serve as one step in a multibarrier approach for water treatment. It may act as a pretreatment step to membrane filtration to reduce the adverse effects of membrane fouling and reduce the costs associated with replacing the membrane apparatus. Additionally, DEP provides an alternative to 
conventional water treatment technologies that are not energy efficient and require the addition of hazardous chemicals.

Although the effects of DEP have been studied extensively for many years using various bioparticles, only a handful of studies have been geared towards water safety applications. iDEP can be used for more than just microfluidic applications. The $6.5 \mathrm{~mL}$ device fabricated and tested in this study serves as a proof-of-concept for the use of glass beads in an iDEP device with a larger liquid throughput and removal efficiency than previously designed devices. The $99.9 \%$ E. coli removal efficiency surpasses the less than 1-log reductions seen with previous devices. iDEP filters can be made with cost-effective insulating materials that are simple to assemble and do not require laborious manufacturing techniques. Further research must be completed in the future to determine the feasibility and practicality of a macroscale glass bead iDEP device to process large quantities of drinking water. Additionally, other waterborne pathogens must be tested to observe their behaviors within the iDEP device.

Author Contributions: Conceptualization, C.C. and S.J.; methodology, C.C.; investigation, C.C.; formal analysis, S.J. and C.C.; resources, K.H. and Y.L.; writing-original draft preparation, C.C.; writing-review and editing, S.J., K.H., and Y.L.; visualization, C.C. and S.J.; supervision, Y.L. All authors have read and agreed to the published version of the manuscript.

Funding: This research received no external funding.

Institutional Review Board Statement: Not applicable.

Informed Consent Statement: Not applicable.

Data Availability Statement: Not applicable.

Conflicts of Interest: The authors declare no conflict of interest.

\section{References}

1. Gleick, P.H. The Human Right to Water. Water Policy 1998, 1, 487-503. [CrossRef]

2. World Health Organization. Progress on Drinking Water, Sanitation and Hygiene: 2017 Update and SDG Baselines. 2017. Available online: https://www.who.int/mediacentre/news/releases/2017/launch-version-report-jmp-water-sanitation-hygiene.pdf (accessed on 20 February 2021).

3. Grey, D.; Sadoff, C.W. Sink or Swim? Water Security for Growth and Development. Water Policy 2007, 9, 545-571. [CrossRef]

4. Falkenmark, M. The Greatest Water Problem: The Inability to Link Environmental Security, Water Security and Food Security. Int. J. Water Resour. Dev. 2001, 17, 539-554. [CrossRef]

5. Mekonnen, M.M.; Hoekstra, A.Y. Four Billion People Facing Severe Water Scarcity. Sci. Adv. 2016, 2, e1500323. [CrossRef] [PubMed]

6. Vörösmarty, C.J.; McIntyre, P.B.; Gessner, M.O.; Dudgeon, D.; Prusevich, A.; Green, P.; Glidden, S.; Bunn, S.; Sullivan, C.A.; Liermann, R.C.; et al. Global threats to human water security and river biodiversity. Nature 2010, 467, 555-561. [CrossRef] [PubMed]

7. Boyce, T.G.; Swerdlow, D.L.; Patricia, M. Griffin Escherichia Coli O157: H7 and the Hemolytic-Uremic Syndrome. N. Engl. J. Med. 1995, 333, 364-368. [CrossRef]

8. Wang, G.; Michael, P. Doyle Survival of Enterohemorrhagic Escherichia Coli O157: H7 in Water. J. Food Prot. 1998, 61, 662-667. [CrossRef]

9. Al-Karaghouli, A.; Kazmerski, L.L. Energy Consumption and Water Production Cost of Conventional and Renewable-EnergyPowered Desalination Processes. Renew. Sustain. Energy Rev. 2013, 24, 343-356. [CrossRef]

10. Shannon, M.A.; Bohn, P.W.; Elimelech, M.; Georgiadis, J.G.; Marinas, B.J.; Mayes, A.M. Science and Technology for Water Purification in the Coming Decades. Nanosci. Technol. A Collect. Rev. Nat. J. 2010, 337-346. [CrossRef]

11. Hua, G.; Reckhow, D.A. Comparison of Disinfection Byproduct Formation from Chlorine and Alternative Disinfectants. Water Res. 2007, 41, 1667-1678. [CrossRef]

12. Boorman, G.A. Drinking Water Disinfection Byproducts: Review and Approach to Toxicity Evaluation. Environ. Health Perspect. 1999, 107, 207-217. [PubMed]

13. van Reis, R.; Zydney, A. Bioprocess Membrane Technology. J. Membr. Sci. 2007, 297, 16-50. [CrossRef]

14. Madaeni, S.S. The Application of Membrane Technology for Water Disinfection. Water Res. 1999, 33, 301-308. [CrossRef]

15. Gao, W.; Liang, H.; Ma, J.; Han, M.; Chen, Z.; Han, Z.; Li, G. Membrane Fouling Control in Ultrafiltration Technology for Drinking Water Production: A Review. Desalination 2011, 272, 1-8. [CrossRef] 
16. Plappally, A.K. Energy Requirements for Water Production, Treatment, End Use, Reclamation, and Disposal. Renew. Sustain. Energy Rev. 2012, 16, 4818-4848. [CrossRef]

17. Kimura, K.; Hane, Y.; Watanabe, Y.; Amy, G.; Ohkuma, N. Irreversible Membrane Fouling during Ultrafiltration of Surface Water. Water Res. 2004, 38, 3431-3441. [CrossRef]

18. Pohl, H.A. Dielectrophoresis: The Behavior of Neutral Matter in Nonuniform Electric Fields (Cambridge Monographs on Physics); Cambridge University Press: Cambridge, UK, 1978.

19. Pethig, R. Dielectrophoresis: Status of the Theory, Technology, and Applications. Biomicrofluidics 2010, 4, 22811. [CrossRef] [PubMed]

20. Pethig, R.; Markx, G.H. Applications of Dielectrophoresis in Biotechnology. Trends Biotechnol. 1997, 15, 426-432. [CrossRef]

21. Hawkins, B.G.; Smith, A.E.; Syed, Y.A.; Kirby, B.J. Continuous-Flow Particle Separation by 3D Insulative Dielectrophoresis Using Coherently Shaped, Dc-Biased, Ac Electric Fields. Anal. Chem. 2007, 79, 7291-7300. [CrossRef]

22. Doh, I.; Cho, Y.-H. A Continuous Cell Separation Chip Using Hydrodynamic Dielectrophoresis (DEP) Process. Sens. Actuators A Phys. 2005, 121, 59-65. [CrossRef]

23. Pamme, N. Continuous Flow Separations in Microfluidic Devices. Lab A Chip 2007, 7, 1644-1659. [CrossRef]

24. Cheng, I.-F.; Chang, H.-C.; Hou, D.; Chang, H.-C. An Integrated Dielectrophoretic Chip for Continuous Bioparticle Filtering, Focusing, Sorting, Trapping, and Detecting. Biomicrofluidics 2007, 1, 21503. [CrossRef] [PubMed]

25. Pohl, H.A.; Crane, J.S. Dielectrophoresis of Cells. Biophys. J. 1971, 11, 711-727. [CrossRef]

26. Srivastava, S.K.; Gencoglu, A.; Minerick, A.R. DC Insulator Dielectrophoretic Applications in Microdevice Technology: A Review. Anal. Bioanal. Chem. 2011, 399, 301-321. [CrossRef] [PubMed]

27. Li, H.; Zheng, Y.; Akin, D.; Bashir, R. Characterization and Modeling of a Microfluidic Dielectrophoresis Filter for Biological Species. J. Microelectromech. Syst. 2005, 14, 103-112. [CrossRef]

28. Cummings, E.B.; Singh, A.K. Dielectrophoresis in Microchips Containing Arrays of Insulating Posts: Theoretical and Experimental Results. Anal. Chem. 2003, 75, 4724-4731. [CrossRef]

29. Baylon-Cardiel, J.L.; Lapizco-Encinas, B.H.; Reyes-Betanzo, C.; Chávez-Santoscoy, A.V.; Martİnez-Chapa, S.O. Prediction of Trapping Zones in an Insulator-Based Dielectrophoretic Device. Lab A Chip 2009, 9, 2896-2901. [CrossRef]

30. Lapizco-Encinas, B.H.; Davalos, R.V.; Simmons, B.A.; Cummings, E.B.; Fintschenko, Y. An Insulator-Based (Electrodeless) Dielectrophoretic Concentrator for Microbes in Water. J. Microbiol. Methods 2005, 62, 317-326. [CrossRef]

31. Masuda, S.; Itagaki, T.; Kosakada, M. Detection of Extremely Small Particles in the Nanometer and Ionic Size Range. IEEE Trans. Ind. Appl. 1988, 24, 740-744. [CrossRef]

32. Cummings, E.B.; Singh, A.K. Dielectrophoretic Trapping without Embedded Electrodes. In Microfluidic Devices and Systems III; SPIE: Bellingham, WA, USA, 2000; Volume 4177, pp. 151-160.

33. Chou, C.-F.; Tegenfeldt, J.O.; Bakajin, O.; Chan, S.S.; Cox, E.C.; Darnton, N.; Duke, T.; Austin, R.H. Electrodeless Dielectrophoresis of Single-and Double-Stranded DNA. Biophys. J. 2002, 83, 2170-2179. [CrossRef]

34. Zhou, G.; Imamura, M.; Suehiro, J.; Hara, M. A Dielectrophoretic Filter for Separation and Collection of Fine Particles Suspended in Liquid. In Proceedings of the Conference Record of the 2002 IEEE Industry Applications Conference, 37th IAS Annual Meeting (Cat. No. 02CH37344), Pittsburgh, PA, USA, 13-18 October 2002; Volume 2, pp. 1404-1411.

35. McGraw, G.J.; Davalos, R.V.; Brazzle, J.D.; Hachman, J.; Hunter, M.; Chames, J.; Fiechtner, G.J.; Cummings, E.B.; Fintschenko, Y.; Simmons, B.A. Polymeric Insulator-Based Dielectrophoresis (IDEP) for the Monitoring of Water-Borne Pathogens. In Proceedings of the ASPE Spring Topical Meeting on Precision Micro/Nano Scale Polymer Based Component and Device Fabrication, ASPE 2005, Cambridge, UK, 18-29 April 2005.

36. Lapizco-Encinas, B.H.; Simmons, B.A.; Cummings, E.B.; Fintschenko, Y. Insulator-Based Dielectrophoresis for the Selective Concentration and Separation of Live Bacteria in Water. Electrophoresis 2004, 25, 1695-1704. [CrossRef] [PubMed]

37. Lapizco-Encinas, B.H.; Simmons, B.A.; Cummings, E.B.; Fintschenko, Y. Dielectrophoretic Concentration and Separation of Live and Dead Bacteria in an Array of Insulators. Anal. Chem. 2004, 76, 1571-1579. [CrossRef]

38. Suehiro, J.; Zhou, G.; Imamura, M.; Hara, M. Dielectrophoretic Filter for Separation and Recovery of Biological Cells in Water. IEEE Trans. Ind. Appl. 2003, 39, 1514-1521. [CrossRef]

39. Cebricos, J.; Hoptowit, R.; Jun, S. Separation of Escherichia Coli K12 from Contaminated Tap Water Using a Single-Stage, Continuous Flow Dielectrophoresis (DEP) Device. LWT 2017, 80, 185-192. [CrossRef]

40. Wang, Z.; Hansen, O.; Petersen, P.K.; Rogeberg, A.; Kutter, J.P.; Bang, D.D.; Wolff, A. Dielectrophoresis Microsystem with Integrated Flow Cytometers for On-Line Monitoring of Sorting Efficiency. Electrophoresis 2006, 27, 5081-5092. [CrossRef]

41. Abidin, Z.Z.; Baik, D.A.; Hafifudin, N.; Markx, G. FACTORS AFFECTING DIELECTROPHORETIC SEPARATION OF CELLS USING HIGH-GRADIENT ELECTRIC FIELD STRENGTH SYSTEM. J. Eng. Sci. Technol. 2008, 3, 30-39.

42. Sankaranarayanan, A.; Sankarlal, K.M.P.; Raja, D. Impact of Different Frequencies in the Entrapment of Bacterial Pathogens from Drinking Water Using Dielectrophoretic Phenomena. J. Water Chem. Technol. 2016, 38, 117-122. [CrossRef]

43. Kang, K.H.; Kang, Y.; Xuan, X.; Li, D. Continuous Separation of Microparticles by Size with Direct Current-Dielectrophoresis. Electrophoresis 2006, 27, 694-702. [CrossRef] [PubMed]

44. Markx, G.H.; Dyda, P.A.; Pethig, R. Dielectrophoretic Separation of Bacteria Using a Conductivity Gradient. J. Biotechnol. 1996, 51, 175-180. [CrossRef] 
45. Wang, X.-B.; Vykoukal, J.; Becker, F.F.; Gascoyne, P.R.C. Separation of Polystyrene Microbeads Using Dielectrophoretic/Gravitational Field-Flow-Fractionation. Biophys. J. 1998, 74, 2689-2701. [CrossRef]

46. Shafiee, H.; Caldwell, J.L.; Sano, M.B.; Davalos, R.V. Contactless Dielectrophoresis: A New Technique for Cell Manipulation. Biomed. Microdevices 2009, 11, 997-1006. [CrossRef] [PubMed] 